Urban Ecosyst (2010) 13:113-127

DOI 10.1007/s11252-009-0107-x

\title{
Making Biodiversity Measures Accessible to Non-Specialists: An Innovative Method for Rapid Assessment of Urban Biodiversity
}

Konstantinos TZOULAS ${ }^{\mathrm{a}}$, Philip JAMES ${ }^{\mathrm{b}}$,

a) Corresponding author: School of Environment and Life Sciences, Peel

Building, University of Salford, Greater Manchester, M5 4WT, UK,

Tel: +44(0) 161295 2133,Fax: +44(0) 161295 2138,k.tzoulas@salford.ac.uk

b) School of Environment and Life Sciences, Peel Building, University of Salford, Greater Manchester, M5 4WT, UK 


\section{Abstract}

Urban biodiversity studies provide important inputs to studying the interactions between human societies and ecological systems. However, existing urban biodiversity methods are time intensive and/or too complex for the purposes of rapid biodiversity assessment of large urban sites. In this paper the authors present a biodiversity assessment method that is innovative in its approach, is reliable, and from which the data generated can be presented in an understandable way to nonecologists. This method is based on measuring the land cover of different vegetation structures and the diversity of vascular plants, and then combining these into an overall biodiversity score. The land cover of vegetation structures was recorded by using a checklist in combination with Tandy's Isovist Technique and the Domin cover scale. Vascular plant diversity was recorded at genus level by walking along defined transects within circular sampling areas of sixty five meter radius and using a checklist. A scoring procedure assigns an overall biodiversity score to different combinations of land cover of vegetation structures and vascular plant diversity. This method was tested in three urban locations in the United Kingdom which differed according to size, design and land use. Descriptive statistics of the resulting biodiversity scores differentiated between the biodiversity distribution within each one of the three locations, as well as across them. The main strength of this rapid biodiversity assessment method is its simplicity. Furthermore, by producing accurate results this biodiversity assessment method can be most useful in rapidly identifying areas where more detailed ecological surveys are needed.

Key words: biodiversity surrogates; biodiversity indicators; Tandy's Isovist Technique; vegetation structure; socio-ecological integration 


\section{Introduction}

The concept of biological diversity was initially defined as the total number of species within a given area (Lovejoy 1980). This was further complemented with the concepts of genetic diversity (Norse and McManus 1980), habitat diversity (Wilson 1988) and cultural diversity (Hawksworth and Kalin-Arroyo 1995). Along with compositional and structural elements the concept of biodiversity also incorporates functional aspects of ecosystems (Noss 1997). Consequently, biodiversity integrates genes, species, habitats, associated interactions and socioeconomic, aesthetic and ethical human values.

The complexity and multiple scale aspects of the concept of biodiversity have led some authors to question its usefulness in ecological studies (Stork and Samways 1995; Jutro 1993). Although challenging to deal with, the multiple scale aspects of biodiversity provide important inputs into increasing current understanding of the distribution and functions of species and habitats (Turner et al. 2005; Gaston et al. 2004; Niemelä 1999; Gilbert 1991).

Urban and peri-urban planning affects all scales at which species, habitats and people interact. Furthermore, planning and biodiversity conservation are guided by and reflect socioeconomic values. So, integrating planning and biodiversity could provide opportunities for addressing both nature conservation and cultural concerns about landscapes (Boothby 2000).

Often biodiversity studies focus on species richness or abundance (Hermy and Cornelis 2000) or on particular indicator species (Pearson 1996). Although detailed biodiversity studies are central in accurately describing urban habitats, they can be time and resource intensive (Pharo et al. 1999). Furthermore, specialist ecological studies may not be readily understood by planners (YliPelkonen and Niemelä 2005; Moss 2000). So, to facilitate the integration of planning and biodiversity simple ecological methods that produce accurate descriptions of urban habitats, in a manner that is understandable with minimal effort by non-ecologists, are needed.

Studies that use vegetation structure as an indicator of biodiversity have the potential to bridge understanding difficulties between disciplines (Whitford et al. 2001; Young and Jarvis 2001; Hercock 1997). Vegetation structure refers to the composition and height variability of trees, shrubs, forbs and grasses in an area. Numerous studies have found that the composition and complexity of habitats could be a good indicator of overall biodiversity (Gaston et al. 2005; Cornelis and Hermy 2004; Honnay et al. 2003; Livingston et al. 2003; Zerbe et al. 2003; Whitford et al. 2001; Hermy and Cornelis 2000; Wessels et al. 1999). Furthermore, the vegetation structure of habitats can link biodiversity with other environmental or ecological indicators, thus integrating the form and function of biodiversity (Whitford et al. 2001). Therefore, vegetation structure, as an indicator of biodiversity, has both ecological credibility and the potential to accurately simplify complex interactions between species and habitats. 
Current methodologies that use vegetation structure as a biodiversity indicator can be time, resource and expertise intensive; and may employ typologies of land use, land cover and vegetation structure that are too detailed or too general to be applied directly to different locations (Gaston et al. 2005; Cornelis and Hermy 2004; Honnay et al. 2003; Livingston et al. 2003; Zerbe et al. 2003; Whitford et al. 2001; Young and Jarvis 2001; Hermy and Cornelis 2000; Hercock 1997). This is why it is important to develop rapid biodiversity assessment methods that are simple, reliable and transferable to different locations.

In this paper the authors develop a biodiversity assessment method that is quick to undertake, it is ecologically credible and requires minimal technical expertise. This method is based on measuring the land cover of different vegetation structures and the diversity of vascular plants in a given area, and combining these into an overall biodiversity score. To assess the applicability of the method it was piloted in three different locations: Birchwood Forest Park (the 200 hectares open space network of a New Town sub-urban development, Warrington, UK);

Alexandra Park (a 24 hectares urban park from the early $20^{\text {th }}$ century, Manchester, UK); and an 8.6 hectare neighbourhood in Whalley Range (an inner city residential area, Manchester, UK). The method was developed between 2004 and 2008 based on repeated visits to the three locations.

\section{Methods}

The method presented here has three stages. First, appropriate checklists for recording urban habitat type, the land cover of vegetation structures and diversity of vascular plant genera were developed. Second, the checklists were filled in during field work which combined Tandy's Isovist technique (Westmacott and Worthington 1994) and the Domin scale of land cover (Sutherland 1996). Third, a technique was developed that combines land cover of vegetation structures and genera diversity of vascular plants into an overall biodiversity score. These stages are explained in the following sections.

\section{The Development of the Checklists}

Checklists of urban habitat types could have the limitation of either being too specific to particular locations to be applied elsewhere or being too general to capture the heterogeneity of urban habitats. In this study a checklist of urban habitat types was developed by combining and editing existing urban habitat typologies developed by Livingston et al. (2003); Honnay et al. (2003); Freeman and Buck (2003); Pauleit and Duhme (2000) and Freeman (1999). The checklist developed here comprises both specific and general urban habitat types. Specific habitat types that can be found in most urban areas were kept as distinct categories. Furthermore, sub-categories for each one of the general habitat types were identified to reflect possible heterogeneity of habitats.

The checklist used to record vegetation structure was developed by combining and editing Elton and Miller's (1954) physiognomic method (quoted in Southwood and Henderson 2000; and in Kent and Coker 1992) with the structural 
categories developed by Freeman and Buck (2003). The height limits of the structural elements were drawn from existing urban planting schemes (e.g. Greenwood and Moffatt 1982).

The checklist of vascular plants genera was developed from secondary data that listed species expected to be found in the areas being sampled. For the UK such data may be obtained via the British Natural History Museum's post-code plants data base (http://www.nhm.ac.uk). Since the method developed here was designed to record the diversity of vascular plants irrespective of human or ecological values associated with them the checklist does not differentiate between native or introduced genera. Using vascular plants as the only indicator group for overall biodiversity is limiting because they may not reflect adequately all other groups of genera in a habitat. Further indicator groups could have been included in the method (e.g. invertebrates, birds, mammals). However, adding more indicator groups would complicate the method as well as increase its time and resource requirements. So, to avoid these drawbacks only vascular plant genera were used in the method. All three checklists were confirmed and amended by field visits to reflect the particular study sites; and then were combined into the field record sheet (Table 1 and Appendix A).

Table 1 The Field Record Sheet Developed for This Study - For Vascular Plant Genera Checklist See Appendix A

\begin{tabular}{|c|c|}
\hline \multicolumn{2}{|l|}{ Habitat types } \\
\hline Built surfaces ${ }^{a}$ & Incidental green space ${ }^{c}$ \\
\hline Cemeteries & Residential area with gardens \\
\hline Churchyards & Residential area with no gardens \\
\hline Civic and market squares & Urban farms ${ }^{\mathrm{d}}$ \\
\hline Commercial/ industrial & Urban park $^{\mathrm{e}}$ \\
\hline Country park ${ }^{\mathrm{b}}$ & Waste land \\
\hline
\end{tabular}

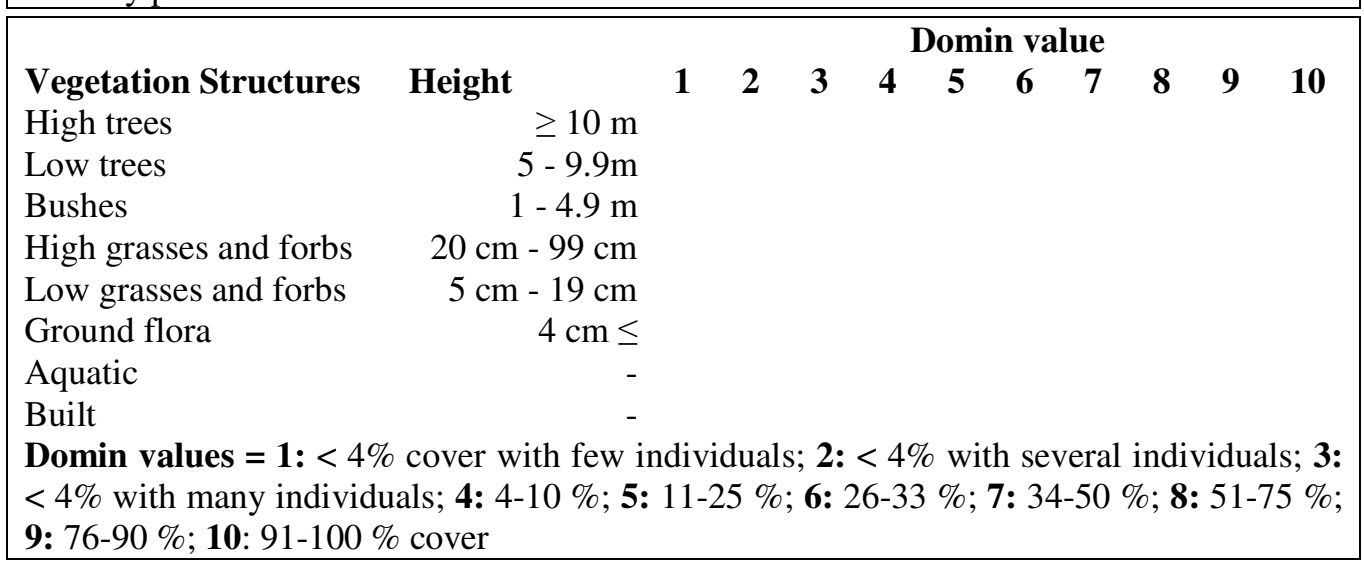

N.B.: a. includes roads; b. includes golf course and local nature reserves; c. includes road side verges, housing green space, pedestrian streets, informal recreational space; d. includes community gardens and allotments; e. includes village greens and formal gardens. 


\section{Measuring Land Cover of Vegetation Structures and Vascular Plant Diversity of Urban Habitats}

The method developed here was designed for urban habitats larger than one hectare. This was justified on two main reasons. First, sites of less than one hectare are small enough such that they might be efficiently assessed in their entirety by existing techniques. Second, the sampling effort associated with sites about one hectare or larger may require significant time and resources that need to be balanced against the type, quality and accuracy of the data collected. Apart from the criterion that the study sites should be larger than one hectare the locations were selected randomly amongst the sites that were available in the Manchester and Warrington urban areas (North West, UK). The random selection of sites led to their sizes varying considerably (Birchwood Forest Park 200 hectares; Alexandra Park 24 hectares; and the neighbourhood in Whalley Range 8.6 hectares).

A simple stratified unaligned sampling strategy was used to identify sampling points within each one of the three study areas (Hill et al. 2005; Yates 1974). Initially, three different sample sizes were tried. Circular samples with radii of $25 \mathrm{~m}$ and $50 \mathrm{~m}$ captured some variability but were found to be liable to being dominated by one or two habitat types and/ or vegetation structures. However, an area with a $65 \mathrm{~m}$ radius was found to be large enough to contain different configurations of habitat types and vegetation structures. Furthermore, for the purposes of rapid biodiversity assessment the latter sample size is more useful than the smaller ones for studying large urban habitats because it could reduce the sampling effort. Larger sampling areas were found to be impractical in urban environments.

Having established the preferred sample size the next step was to identify how many sampling points were appropriate for each study site. Two criteria were used at this stage. First, the sampling area for each site was to be larger than $10 \%$ of the site (Hill et al. 2005; Yates 1974). Second, the number of sampling points at each site should capture the variability within that site. In order to establish the inherent variability within the sites a total of 23 sampling points were established in Birchwood Forest Park; nine in Alexandra Park; and four in the Whalley Range neighbourhood.

Descriptive statistics were performed using Microsoft Excel $\mathrm{XP}^{\circledR}$ Professional Edition 2003 to summarise the biodiversity indicators and describe their distribution across the study locations. The occurrence of different habitat types across the case study locations was calculated as a percentage of the total number of sampling points at each location.

The land cover of different vegetation structures was recorded using Tandy's Isovist technique (Westmacott and Worthington 1994). This technique visually estimates land cover within a defined visual horizon. First, a visual horizon needs to be defined. In this study the visual horizon was each circular sampling plot with a $65 \mathrm{~m}$ radius. To delineate each sampling plot a measuring tape was used to establish radii of $65 \mathrm{~m}$ from a central landmark. From each central landmark four radii were measured running from north to south and from east to west as well as from south west to north east and from south east to north west. The end of each 
radius was marked and these marks were used to indicate the boundaries of the sampling plots.

Second, within each sampling plot (i.e. the visual horizon) the land cover of different vegetation structures was recorded. Using the Domin scale of cover (Sutherland 1996) the proportions of land cover of different vegetation structures were visually estimated and recorded on the field sheet either from a central point (if that offered uninterrupted views of the whole sampling plot) or by walking around the sampling area (if there were tall vegetation structures or buildings interrupting the views). This combination of techniques is effectively a landscape scale version of visual estimates of vegetation cover: i.e. it is based on visual estimates of vegetation cover in a sample area of $13,266 \mathrm{~m}^{2}$. The mean land cover (i.e. Domin value) for each one of the vegetation structures was calculated and this mean value was used to allocate points in the scoring procedure.

The next step of the method involved identifying and recording the genera of vascular plants. Each one of the four radii that were established to delineate the sampling plots was used as a ten meter wide transect along which vascular plants were identified. Each transect was walked four times to identify and record grasses, forbs, shrubs and trees in turn. Vascular plants that formed the main components of the vegetation structures and/ or were visually prominent were identified by using ecological field guides (Mitchell 2006; Aas and Riedmiller 2001; Lippert and Podlech 1994; Fitter et al. 1984) and were recorded on the field record sheet. Botanical knowledge at least at a level of identifying vascular plants was needed for this survey (i.e. grasses, forbs, shrubs and trees). Visits were designed to capture different flowering seasons as well as variations in the vegetation structures. The range and mean for the diversity of vascular plants genera at each study area were computed.

\section{Combining Indicators into Biodiversity Scores}

In order to integrate the indicators and illustrate the distribution of biodiversity within the study areas in a simple and non-technical way a technique was developed, which combines the surrogates of vegetation structure and vascular plant diversity into an overall biodiversity score.

A technique developed by Young and Jarvis (2001) has the advantage of recording a wide range of structural elements of habitats; however it does not record their spatial proportions. Another technique used a modified ShannonWeiner index of habitat heterogeneity as an indicator of biodiversity, based on records of the spatial proportions of a limited range of structural elements (Whitford et al. 2001). The main weakness of the Shannon-Weiner index is its premise that the more equal the proportion of structural elements the higher the index. Although equal proportions of, for example, built areas and woodland areas may reflect the same habitat heterogeneity with equal proportions of shrubs and woodland areas, the second combination of land cover has a higher biodiversity potential than the first one. Consequently, it was decided to develop a technique that incorporated a wide range of structural elements, and took into account the spatial proportion of built areas and the number of vascular plants. 
The procedure developed here comprises four steps and is outlined in Table 2. Table 3 includes data from the first three sampling points from Birchwood Forest Park and illustrates the application of the procedure.

Table 2 Procedure for Combining Structural Elements and Diversity of Vascular Plants General Into an Overall Biodiversity Score

\section{Step 1: For every vegetation structure present}

+1 point (irrespectively of Domin scale cover of each structural element)

\section{Step 2: On the resulting scores}

Add or subtract points according to built cover -1 point for built layer Domin 6; -2 for built layer Domin 7; -3 for built layer Domin 8; -4 for built layer Domin 9; -5 for built layer Domin 10;

+1 point for built layer Domin 5; +2 for built layer Domin 4; +3 for built layer Domin 3; +4 for built layer Domin 2; +5 for built layer Domin 1 .

\section{Step 3: On the resulting scores}

+1 point for every six different vascular plant genera present

0 points for no genera present;

1 point for $\leq 6$ genera;

2 points for 7-12 genera;

4 points for $19-24$ genera;

5 points for 25-30 genera;

3 points for 13-18 genera;

\section{Step 4: Sum final biodiversity score}

Sum the scores resulting from steps 1 to 3

Table 3 Worked Example of The Biodiversity Scoring Procedure from The First Three Sampling Points in Birchwood Forest Park

Vegetation structures (mean Domin value) \& Vascular plants genera (number)

High trees

Low trees

Bushes

High grasses and forbs

Low grasses and forbs

Ground flora

Aquatic

Built

\section{Sampling point}

Vascular plants genera

\section{Scoring procedure}

(see Table 2)

Step 1: +1 point (irrespectively of Domin scale cover of each structural element)

Step 2: Add or subtract points according to built cover

Step 3: +1 point for every six different vascular plant genera present

Step 4: Sum the scores resulting from steps 1 to 3

$\begin{array}{rrr}\mathbf{1} & \mathbf{2} & \mathbf{3} \\ 2 & 2 & 0 \\ 5 & 7 & 4 \\ 4 & 5 & 5 \\ 4 & 4 & 3 \\ 5 & 5 & 6 \\ 4 & 4 & 0 \\ 0 & 0 & 0 \\ 6 & 0 & 7 \\ 30 & 31 & 25\end{array}$


The biodiversity potential of a built surface is not comparable to that of a nonbuilt surface. This is why at the second step points are either added or subtracted depending on the proportion of the built cover. The break-point of $33 \%$ of built cover (Domin scale 6) was chosen because this leaves two thirds of the sampling area to be covered by seven potential other vegetation structures. High proportions of built cover within a sampling area would reduce its biodiversity (Godefroid and Koedam 2007), and so points are subtracted if the built cover is equal to, or higher than Domin scale 6; while points are added if the built cover is less than Domin scale 6. For every Domin scale above or below 6 one point is subtracted or added respectively (Table 2 ).

The number of vascular plants genera in each sampling point is taken into consideration in the third stage of the procedure. A minimum of thirteen genera were recorded in a sampling point. Allocating 1 point for every 13 different genera (i.e. 0 points for no genera present; 1 point for $\leq 13$ genera; 2 points for 14 27 genera and so on) did not result in much variation in biodiversity scores. However, by allocating 1 point for every 6 different genera (see Table 2) it was possible to capture better the small variability in vegetation communities within the case study locations. So, this break point was used for the final analysis (i.e. 0 points for no genera present; 1 point for $\leq 6$ genera; 2 points for 7-12 genera; 3 points for 13-18 genera and so on). However, different break points may be appropriate to different study sites based on their local vascular plant diversity. At the final stage the scores from stages one, two and three are added. The range and mean for the overall biodiversity scores for the study areas was computed.

The sum of biodiversity scores across the sampling areas of each study location was used as the total biodiversity score in this study. This was decided because there were different number of sampling areas across the different locations, and so the mean biodiversity score values would not be representative. On sites of equal size and number of sampling areas the mean could also be used as the overall biodiversity score.

Since even built surfaces have potential for colonisation by plants and animals, the biodiversity scores procedure was constructed in a way that excluded negative biodiversity scores. For instance, a theoretical sampling point with $99 \%$ built cover (Domin scale 10), $1 \%$ tree cover, and less than 6 vascular plant genera would score 3 points (i.e. +2 for the two layers present and +1 for the vascular plants). So, the theoretical minimum biodiversity score, for an area with $100 \%$ built cover and no plant genera present, would be 1 . There is no maximum biodiversity score as this depends on the actual number of plant genera in a given area. Having no maximum biodiversity score may work for this method which is aimed at giving an indicator of the diversity of plants and ecological niches of a given habitat rather than its actual ecological value. Where the ecological value is sought ratios of observed to expected vascular plant genera could also be used.

In order to test that this technique was producing meaningful and accurate results it was applied at two specific areas with known plant and animal diversity within Birchwood: the moss-land area of Risley Moss Local Nature Reserve (total 130 species of plants and animals and with a simple vegetation structure; Risley Moss Action Group unpublished data), and the Birchwood Shopping Centre Wildlife Garden (total 70 species of plants and animals and with a complex vegetation 
structure; Birchwood Shopping Centre unpublished data). By applying the technique Risley Moss scored higher (overall biodiversity score 10) than the Wildlife Garden (overall biodiversity score 8).

\section{Results}

The habitat type checklist shown in Table 1 includes twelve broad habitats each one of which could be internally heterogeneous (Table 4). Birchwood Forest Park had seven different habitat types with the most prominent being incidental green space which was found in ten out of twenty three sampling points $(43 \%)$ and residential areas with no gardens which was found in seven out of twenty three sampling points (30\%). The neighbourhood in Whalley Range was characterised by two habitat types (i.e. residential areas with gardens and incidental green space) and Alexandra Park by a single type (i.e. urban park; Table 4). Urban habitat types recorded for descriptive purposes but where not included in the scoring as this may have incorporated human associated values in the procedure.

The land cover of vegetation structures was more consistent than the composition of habitat types across sampling points in the different study locations (Table 4). Land cover in Birchwood Forest Park was dominated by amenity grasslands and low trees each with a mean Domin value of 5 (i.e. $11 \%-25 \%$ cover), while the vegetation structure of Alexandra Park was characterised by amenity grassland (Domin value 7; 34\% - 50\% cover) and high trees (Domin value 6; 26\% - 33\% cover; Table 4). On the other hand, the neighbourhood in Whalley Range was mainly built areas (Domin value $8 ; 51 \%$ - 75\% cover) but with equal mean Domin values for most of the other vegetation structures (Domin value 5; 11\% - 25\% cover).

The diversity of vascular plants genera was also consistent across the study locations as indicated by the mean number of genera at each site (Table 4). The highest vascular plant diversity was recorded in Birchwood (23.4 mean number of genera) and the lowest in Alexandra park (21.1 mean number of genera). The neighbourhood in Whalley Range had a narrower range than Birchwood and Alexandra Park. This reflects the small size of the former in relation to the latter locations.

The vegetation structure of each sampling point along with the number of its different vascular plant genera were combined according to the method explained in Table 2 to give an overall score, as a surrogate for biodiversity. Birchwood was the largest of the three locations and so it showed a greater variability of biodiversity scores across its sampling points than the variability within Alexandra Park and the Whalley Range neighbourhood (see also Table 4).

Reflecting the size of each location, Birchwood had the highest biodiversity score (sum score 207), followed by Alexandra Park (sum score 92) and then the neighbourhood in Whalley Range (sum score 30; Table 4). Since the method designed here was aimed at capturing the habitat heterogeneity of large sites (larger than one hectare) it was expected that Birchwood Forest Park would score higher than the smaller ones. The relatively small differences in the mean 
Table 4 Summary Results of Biodiversity Indicators and Biodiversity Scores in Three Study Locations

\section{Birchwood Alexandra Park Neighbourhood}

Habitat type $^{\text {a }}$

Commercial/ industrial

Residential/ no gardens

Residential/ gardens

Incidental green space

Urban park

Golf course

Local Nature Reserve

Vegetation structures

High trees

Low trees

Bushes

High grasses and forbs

Low grasses and forbs

Ground flora

Aquatic

Built

Genera diversity

Min

Max

Mean

Biodiversity score

Min

Max

Mean

Sum score ${ }^{d}$
Percent of sampling points

$$
(\mathrm{n}=9) \quad(\mathrm{n}=4)
$$

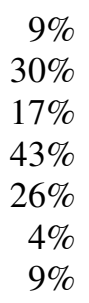

$0 \%$
$0 \%$
$0 \%$
$0 \%$
$100 \%$
$0 \%$
$0 \%$

$0 \%$

$0 \%$

$100 \%$

$100 \%$

$0 \%$

$0 \%$

$0 \%$
Mean Domin values ${ }^{b}$

$\begin{array}{ll}6 & 4 \\ 4 & 5 \\ 4 & 5 \\ 4 & 5 \\ 7 & 5 \\ 1 & 1 \\ 1 & 0 \\ 5 & 8\end{array}$

(a) In Birchwood and Whalley Range because of some habitat types being in more than one sampling points the sums do not add up to $100 \%$; (b) This is the mean between winter and summer surveys across all sampling plots per study site; Domin values $=1:<4 \%$ cover with few individuals; $2:<4 \%$ cover with several individuals; $3:<4 \%$ cover with many individuals; $4: 4-10$ \% cover; 5: 11-25 \% cover; 6: 26-33 \% cover; 7: 34-50 \% cover; 8: 51-75 \% cover; 9: 76-90 \% cover; 10: $91-100 \%$ cover); (c) This is the range across all sampling plots per study site; (d) This is the sum of scores across all sampling plots per study site.

biodiversity scores of the three locations most probably reflect their horticultural heritage. Birchwood was designed according to naturalistic design principles which emphasised native habitat (re-)creation (Scott 1991); while Alexandra Park (an English Edwardian Park) and Whalley Range (a Victorian suburb with gardens and tree avenues) both have a long history of ornamental planting. 
In order to effectively assess a site it is important to capture the total variability present. Table 5 presents data that demonstrates how the data collected from each site varied as the number of samples increased. It suggests that the optimum sampling strategy would have been to use 19,6 and 3 samples in Birchwood, in Alexandra Park and in the neighbourhood in Whalley Range respectively. Based on this optimum sampling strategy it would take just over twelve days to plan, conduct and report on the survey of the 24.7 hectares of sampling area in Birchwood Forest Park (total site area 200 hectares; Table 6). This compares very favourably to other methods: for example that developed by Hermy and Cornelis, (2000) which required thirty three days per twenty five hectares studied.

Table 5 Sampling Effort Required in Three Study Locations

\begin{tabular}{|c|c|c|c|c|c|c|c|c|c|}
\hline \multirow[b]{2}{*}{$\begin{array}{c}\text { no. of } \\
\text { samples }\end{array}$} & \multicolumn{3}{|c|}{ Birchwood } & \multicolumn{3}{|c|}{ Alexandra Park } & \multicolumn{3}{|c|}{$\begin{array}{l}\text { Whalley Range } \\
\text { Neighbourhood }\end{array}$} \\
\hline & $\mathbf{m}$ & $\mathbf{r}$ & $\mathbf{g}$ & $\mathbf{m}$ & $\mathbf{r}$ & $\mathbf{g}$ & $\mathbf{m}$ & $\mathbf{r}$ & $\mathbf{g}$ \\
\hline 1 & 7 & 0 & 23 & 7 & 0 & 34 & 7 & 0 & 30 \\
\hline 2 & 6 & 1 & 26 & 7 & 0 & 41 & 6 & 1 & 34 \\
\hline 3 & 4 & 3 & 26 & 7 & 1 & 44 & 6 & 1 & 36 \\
\hline 4 & 6 & 3 & 26 & 7 & 1 & 45 & 6 & 1 & 36 \\
\hline 5 & 6 & 4 & 26 & 7 & 1 & 45 & & & \\
\hline 6 & 6 & 4 & 27 & 7 & 1 & 48 & & & \\
\hline 7 & 4 & 4 & 27 & 6 & 1 & 48 & & & \\
\hline 8 & 4 & 5 & 27 & 6 & 3 & 48 & & & \\
\hline 9 & 4 & 5 & 27 & 7 & 3 & 48 & & & \\
\hline 10 & 6 & 5 & 27 & & & & & & \\
\hline 11 & 6 & 5 & 28 & & & & & & \\
\hline 12 & 6 & 5 & 28 & & & & & & \\
\hline 13 & 6 & 5 & 28 & & & & & & \\
\hline 14 & 6 & 5 & 29 & & & & & & \\
\hline 15 & 6 & 5 & 30 & & & & & & \\
\hline 16 & 6 & 5 & 33 & & & & & & \\
\hline 17 & 6 & 5 & 37 & & & & & & \\
\hline 18 & 6 & 5 & 43 & & & & & & \\
\hline 19 & 6 & 5 & 43 & & & & & & \\
\hline 20 & 6 & 5 & 43 & & & & & & \\
\hline 21 & 6 & 5 & 43 & & & & & & \\
\hline 22 & 6 & 5 & 43 & & & & & & \\
\hline 23 & 6 & 5 & 43 & & & & & & \\
\hline
\end{tabular}

Key: $\mathrm{m}=$ the mode of the number of vegetation structures recorded with increasing amounts of sampling effort; $r=$ the range of the number of vegetation structures recorded with increasing amounts of sampling effort; $g=$ the number of vascular plant genera recorded with increasing amounts of sampling effort. 
Table 6 Time Required For Employing The Method

$\begin{array}{lccr}\text { Size of area } & \text { Birchwood } & \begin{array}{c}\text { Alexandra } \\ \text { Park }\end{array} & \begin{array}{c}\text { Whalley R } \\ \text { Neighbour }\end{array} \\ \text { Study area (hectares) } & 200.0 & 24.0 & 8.6 \\ \text { Number of Sampling points } & 19.0 & 6.0 & 3.0 \\ \text { Sampling area (hectares) } & 24.7 & 7.8 & 3.9 \\ \text { \% of study area sampled } & 12.3 & 32.5 & 45.3 \\ & & & \\ \text { Number of day required } & & & \\ \text { Field work preparation } & 3.0 & 2.0 & 1.0 \\ \text { Field visits } & 7.6 & 2.4 & 1.2 \\ \text { Analysis } & 1.0 & 0.7 & 0.5 \\ \text { Reporting } & 0.5 & 0.3 & 0.2 \\ \text { Total } & 12.1 & 5.4 & 2.9\end{array}$

N.B.: (a) this is based on two visits per sampling point (one visit in winter and one in summer) and spending an average 1.5 hours at each sampling point; work day based on 7.5 working hours.

\section{Discussion}

The method presented here is based on measuring the land cover of different vegetation structures and the diversity of vascular plant genera, and combining these into an overall biodiversity score for a site. The structural composition of habitats is often used as a surrogate for biodiversity (Cornelis and Hermy 2004; Honnay et al. 2003; Livingston et al. 2003; Zerbe et al. 2003; Hermy and Cornelis 2000). However, existing studies use vegetation structure or habitat typologies that are too detailed or too general for applying directly to different locations. This challenge has been overcome by the method proposed here which is based on edited extant habitat type and land cover typologies.

During fieldwork only vascular plants genera that formed the main components of the vegetation structure and/ or were visually prominent along specified transects were recorded. However, since there could be plant genera that were not a main part of the vegetation structures or visible to the observer, as well as due to the varying number of species that may be included in different genera, this method may not be very accurate. A detailed biodiversity study has found a mean 119 species per average urban garden in the UK. The range of that study was 48-268 species (Gaston et al. 2004). Furthermore, in an outer suburb area the size of Birchwood Forest Park a mean of around 350 species would be expected (Gilbert 1991).

If it is assumed that each plant genus recorded in this study contained a mean of five species, then the method reported here yielded a range of 105 to 115 plant species per sampling area (circa 1.3 hectares). However, since this method is not intended to replace detailed ecological studies these results were considered sufficient enough for a rapid biodiversity assessment. It is hoped that this method will be used to identify areas where more detailed ecological surveys are needed.

Even though some botanical knowledge in the identification of trees, shrubs, forbs and grasses is required in this method this is not as time and resource intensive as detailed botanical studies can be. Furthermore, the lack of the need for specialist 
field equipment, analytical software or statistical techniques makes this method particularly simple to undertake. The analysis involves simple descriptive statistics that are readily understood by different disciplines and lay-people.

Since the number of different habitat types in the study locations was not considered in the biodiversity score, and since all of the structural elements were present at each location, the differences in the biodiversity scores must be attributable to the diversity of vascular plants and to the size of each location. The mean number of vascular plants genera between the three study sites was not dissimilar. This was probably due to Birchwood being designed according to naturalistic design principles (Scott 1991); and due to Alexandra Park and the neighbourhood in Whalley Range having long horticultural traditions. Therefore, the differences in biodiversity across the study sites may be due to the differences in their sizes, as well as due to differences in the percent cover of built areas.

In urban areas vegetation is often used as an architectural or structural element. Plants and groups of plants are used to promote certain functions of the urban landscape in a consistent manner (e.g. shelter, screen, semi-barriers, overhead enclosure, shadow, deflected vistas; Scott 1991; Greenwood and Moffatt 1982). Additionally, maintenance and management techniques were (and are) aimed at maintaining these functions, which means that the vegetation structures in urban areas are not random but serve certain purposes. By integrating the structural elements of urban habitats with the number of vascular plant genera, this methodology, has the potential to reveal relationships between maintenance and management techniques and biodiversity patterns in urban areas. Such relationships could be important in understanding the impact of human intervention on the structure and function of urban ecosystems.

This method is limited by its reliability on field work. In urban areas many of the potential sampling sites may not be accessible for ecological sampling. This could be overcome by adjustments to the sampling strategy and/ or to the sample size. Furthermore, the larger the area to which this method is applied or the more the additional indicators groups that may be incorporated (e.g. invertebrates, mammals or birds) the more will be the increase in the times and associated costs that would be required.

The methodology developed here could be applied directly, or with minor modifications, in other urban areas. For instance, the method could be applied directly in comparing the biodiversity scores of large urban habitats in Manchester and in Warrington (UK) for which the vascular plant genera checklist was developed. If the method was to be applied in other urban areas, or if another or additional taxonomic level(s) were used, then the genera checklist (Appendix A) must be amended to reflect new local vegetation communities. This adjustment could be done by using secondary published data and/ or through site visits. Depending on the availability of secondary data or the requirement for site visits the times and costs could also be increased. Furthermore, the technique was designed for urban site larger than one hectare. For smaller sites the radius of the circular sample should be reduced accordingly.

The proposed method is quantitative. This may have the advantage of simplifying complex ecological concepts. However, it also has the limitation of not 
differentiating between qualitative aspects of urban habitats. For instance, it may be that a habitat that is valuable due to its rarity but has a simple structure and low vascular plant diversity scores low overall biodiversity points. Although, the procedure is not differentiating between ecological values of urban habitats, it is not intending to equate them with a numeric score either. Instead the biodiversity scores give an indication of the diversity of plants and habitats in an urban area, and possibly of the need for further detailed studies, rather than its ecological or human value.

The method that was developed in this study takes forward existing methodologies in biodiversity assessment of urban habitats (Gaston et al. 2005; Cornelis and Hermy 2004; Honnay et al. 2003; Livingston et al. 2003; Zerbe et al. 2003; Whitford et al. 2001; Young and Jarvis 2001; Hermy and Cornelis 2000; Hercock 1997) in three main ways. First, it applies visual estimates of vegetation cover at the landscape scale. Second, it incorporates a wide range of structural elements and it takes into account the spatial proportion of built areas and the number of vascular plants in developing a composite biodiversity score. Thirdly, it provides a framework on which further taxonomic groups (e.g. beetles) or levels (e.g. species) could be added for detailed ecological studies.

\section{Conclusion}

In this paper a rapid biodiversity assessment method was presented that links the structural composition of urban areas and the number of vascular plants genera into an overall biodiversity score. This new method improves on current rapid biodiversity assessment methodologies (Cornelis and Hermy 2004; Livingston et al. 2003; Honnay et al. 2003; Zerbe et al. 2003; Young and Jarvis 2001; Whitford et al. 2001; Hercock 1997) by being quick and simple to apply; and by summarising some of the complexity of the multi-scale levels of biodiversity into an overall biodiversity score. A single biodiversity score has the main advantage of being easily understood by non-ecologists. Piloting this method in three study locations of very different sizes it was possible to demonstrate that it can summarise biodiversity indicators within as well as across study sites; and that it could be applied directly, or with minor modifications, in other urban areas. Therefore, this method could be most valuable in situations where rapid assessment of biodiversity is needed; in aiding ecologists working in interdisciplinary projects with limited time and budgets; and in informing planners and urban decision makers.

\section{References}

Aas G, Riedmiller A, (2001) Trees of Britain and Europe. Harper Collin Publishers, London.

Boothby J (2000) An Ecological Focus for Landscape Planning. Landsc. Res. 25, 3, 281-289.

Cornelis J Hermy M, (2004) Biodiversity Relationships in Urban and Suburban Parks in Flanders. Landsc. Urban Plann. 69, 385-401. 
Fitter RSR, Fitter A, Farer A, (1984) Grasses, sedges, rushes, and ferns of Britain and Northern Europe. Harper Collin Publishers, London.

Freeman C (1999) Development of a Simple Method for Site Survey and Assessment in Urban Areas. Landsc. Urban Plann. 44, 1-11.

Freeman C, Buck O (2003) Development of an Ecological Mapping Methodology for Urban Areas in New Zealand. Landsc. Urban Plann. 63, 161-173.

Gaston KJ, Warren PH, Thompson K, Smith RM (2005) Urban domestic gardens (IV): the extent of the resource and its associated features, Biodivers. Conserv. 14, 3327-3349.

Gaston KJ, Smith RM, Thompson K, Warren PH (2004) Gardens and wildlife: The BUGS Project. Br. Wildl. October; 1-9.

Gilbert EO (1991) The ecology of urban habitats. Chapman and Hall, Cambridge.

Godefroid S, Koedam N (2007) Urban plant species patterns are highly driven by density and function of built-up areas. Landsc. Ecol. 22, 1227-1239.

Greenwood RD, Moffatt JD (1982) Implementation techniques for more natural landscapes, in Ruff, A.R., and Tregay, R., (Eds.), An ecological approach to urban landscape design. Occasional Paper No. 8. Department of Town \& Country Planning, The University of Manchester; Manchester.

Hawksworth DL, Kalin-Arroyo MT (1995) Magnitude and distribution of biodiversity, in Heywood, V.H, Watson, R.T., (Eds), Global biodiversity assessment. Section 3. Cambridge University Press and UNEP, Cambridge.

Hercock MJ (1997) Appreciating the biodiversity of remnant bush land: an 'architectural' approach. Environmentalist. 17, 4, 249-258.

Hermy M, Cornelis J (2000) Towards a monitoring method and a number of multifaceted and hierarchical biodiversity indicators for urban and suburban parks. Landsc. Urban Plann. 49, 149162.

Hill D, Fasham M, Tucker G, Shewry M, Shaw P (Eds.) 2005. Handbook of biodiversity methods: survey, evaluation and monitoring. Cambridge University Press, Cambridge.

Honnay O, Piessens K, Van Landuyt W, Hermy M, Gulinck H (2003) Satellite based land use and landscape complexity indices as predictors for regional plant species diversity. Landsc. Urban Plann. 63, 241-250.

Jutro PR (1993) Human influences on ecosystems: dealing with biodiversity, in Mc Donnel, M.J., Pickett, S.T.A. (Eds.), Humans as components of ecosystems. Springer, New York, pp. 246-256.

Kent M, Coker P (1992) Vegetation description and analysis: a practical approach. John Wiley and Sons, London.

Lippert W, Podlech D, (1994) Wild flowers of Britain and Europe. Harper Collin Publishers, London.

Livingston M, Sha WW, Haris LK (2003) A model for assessing wildlife habitats in urban landscapes of Eastern Pima County, Arizona (USA). Landsc. Urban Plann. 64, 131-144.

Lovejoy TE (1980) Changes in biological diversity, in Barney, G.O., (Ed.) The global 2000 report to the president, Vol 2. Penguin Books, Washington DC.

Mitchell K, (2006) Field guide to trees and shrubs of Britain and Europe. New Holland Publishers (UK), London. 
Moss MR (2000) Interdisciplinarity, landscape ecology and the 'transformation of agricultural landscape'. Landsc. Ecol. 15, 303-311.

Niemelä $\mathbf{J}$ (1999) Is there a need for a theory of urban ecology? Urban Ecosyst. 3, 57-65.

Norse EA, MacManus RE (1980) Ecology and living resources: biological diversity, in CEQ, environmental quality 1980: the eleventh annual report of the Council on Environmental Quality. Council on Environmental Quality, Washington DC.

Noss RF (1997) Hierarchical indicators for monitoring changes in biodiversity, in Meffe, G.F., Caroll, C.R. (Eds.), Principles of conservation biology, Second ed. Sinauer Associates, Sunderland, pp. 88-89.

Pauleit S, Duhme F (2000) Assessing the environmental performance of land cover types for urban planning. Landsc. Urban Plann. 52; 1-20.

Pearson DL (1996) Selecting indicator taxa for the quantitative assessment of biodiversity, in Hawksworth, D.L. (Ed.), Biodiversity: measurements and estimation. Chapman and Hall, London, pp. 75-79.

Pharo EJ, Beattie AJ, Binns D (1999) Vascular plant diversity as a surrogate for bryophyte and lichen diversity. Conserv. Biol. 13, 282-292.

Scott D, (1991) The greening of Warrington. Landsc. Des. February, 24-25.

Southwood TRE, Henderson PA (Eds.) (2000) Ecological methods, Third ed. Blackwell Science, London.

Stork NE, Samways MJ (1995). Inventorying and monitoring, in Heywood, V.H. (Ed.), Global biodiversity assessment. Cambridge University Press, Cambridge, pp. 459-543.

Sutherland WJ (Ed.) (1996) Ecological census techniques: a handbook. Cambridge University Press, Cambridge.

Turner K, Lefler B, Freedman B (2005) Plant communities of selected urbanised areas of Halifax, Nova Scotia, Canada. Landsc. Urban Plann. 71, 191-206.

Wessels KJ, Freitag S, Van Jaarsveld AS (1999) The use of land facets as biodiversity surrogates during reserve selection at a local scale. Biol. Conservat. 89, 21-38.

Westmacott R, Worthington T (1994) Agricultural landscapes: a third look. Countryside Commission, Northampton.

Whitford V, Ennos AR, Handley JF (2001) City form and natural processes: indicators for the ecological performance of urban areas and their application to Merseyside, UK. Landsc. Urban Plann. 20, 91-103.

Wilson EO, (Ed.) (1988) Biodiversity. National Academy Press; Washington DC.

Yates M, (1974) An introduction to quantitative analysis in human geography. Mcgraw-Hill Book Company; New York.

Yli-Pelkonen V, Niemelä J, (2005) Linking ecological and social systems in cities: urban planning in Finland as a case. Biodivers. Conserv. 14, 1947-1967.

Young CP, Jarvis PJ (2001) Assessing the structural heterogeneity of urban areas: an example from the Black Country (UK). Urban Ecosyst. 1, 49-69.

Zerbe S, Maurer U, Schmitz S, Sukopp S (2003) Biodiversity in Berlin and its potential for nature conservation. Landsc. Urban Plann. 62, 139-148. 


\section{Grasses and forbs}

Achillea spp

Agrostis spp

Alchemilla spp

Alisma spp

Alliaria spp

Apium spp

Artemisia spp

Bellis spp

Brassica spp

Bromus spp

Calystegia spp

Campanula spp

Centaurea spp

Centaurium spp

Chelidonium spp

Cirsium spp

Daucus spp

Dianthus spp

Digitalis spp

Epilobium spp

Euphorbia spp

Festuca spp

Filipendula spp

\section{Trees and shrubs}

Abies spp

Acer spp

Aesculus spp

Alnus spp

Betula spp

Calluna spp

Carpinus spp

Cedrus spp

Cornus spp

Corylus spp

Crataegus spp

Cupressus spp

Cytisus spp

Daphne spp

Erica spp
Galium spp

Geranium spp

Hedera spp

Heracleum spp

Holcus spp

Humulus spp

Hypericum spp

Juncus spp

Lathyrus spp

Leontodon spp

Lepidium spp

Lolium spp

Lonicera spp

Lotus spp

Lysimachia spp

Malva spp

Matricaria spp

Medicago spp

Myosotis spp

Narcissus spp

Oxalis spp

Papaver spp

Phleum spp

Eucalyptus spp

Fagus spp

Frangula spp

Fraxinus spp

Genista spp

Ilex spp

Laburnum spp

Larix spp

Ligustrum spp

Magnolia spp

Malus spp

Pinus spp

Platanus spp

Populus spp

Prunus spp
Phleum spp

Plantago spp

Poa spp

Potentilla spp

Prenanthes spp

Primula spp

Prunella spp

Pteridium spp

Ranunculus spp

Rhinanthus spp

Rumex spp

Saxifraga spp

Sedum spp

Senecio spp

Sonchus spp

Taraxacum spp

Trifolium spp

Typha spp

Urtica spp

Veronica spp

Vicia spp

Viola spp

Quercus spp

Rhamnus spp

Rosa spp

Rubus spp

Salix spp

Sambucus spp

Sorbus spp

Taxus spp

Thuja spp

Tilia spp

Ulex spp

Ulmus spp

Viburnum spp 